\title{
A GEOSPATIALLY DISTRIBUTED E-REFUGEE CAMP TECHNOLOGICAL FRAMEWORK FOR CARIBBEAN SMALL ISLAND STATES \\ Keisha Gaspard-Chickoree
}

\author{
Faculty of Engineering, The University of the West Indies, Trinidad
}

Email: keisha.chickoree@open.uwi.edu

\begin{abstract}
As a result of the ongoing humanitarian crisis in Venezuela, the country has seen a mass exodus of persons into neighbouring Caribbean Small Island Developing States, SIDS, such as Trinidad and Tobago and Curaçao. These SIDS do not have the infrastructure or local policies to implement a traditional refugee camp within their shores. Findings have shown the many disadvantages to existing or traditional refugee camp settlements. However, as forced migrants continue to pour into these Caribbean states, a technological framework is necessary to capture, manage and connect forced migrants to food and shelter using Geographical Information System, GIS, enabled web technology. Thus, the Geospatially Distributed e-Refugee Camp, GDEC, framework aims to define a burden-sharing model between non-profitable organizations and the government utilizing a free and open source software approach to foster citizen participation and rapid development. The framework is developed using well-defined and tested software development methodologies - Lean Startup Methodology and Rapid Application Development. It analyzes existing technologies used by the UNHCR to represent migration and related GIS data on the web. GDEC is a digitized spatial representation, using a service oriented architecture, of forced migrants housed across the island, the volunteers, safe zones and other relevant stakeholders within the system. This camp, though electronic and distributed, adheres to the standards set by the UNHCR and Sphere for refugee camp settlements. The framework will allow SIDS to roll out a software solution rapidly to meet the urgency of the refugee problem.
\end{abstract}

Keywords: Caribbean small island developing states; Electronic refugee camp; Forced migrants; GeoForms registration; GIS web technology;

\section{https://doi.org/10.47412/BFXS7614}

\section{Introduction}

Venezuela's ongoing humanitarian crisis has found an exodus of 1 million Venezuelans a year fleeing the country, and due to the proximity, SIDS (Small Island Developing States) within the Caribbean, specifically, Trinidad and Tobago, Curacao, Dominican Republic, Aruba and Guyana are all facing the large influx of forced migrants. Caribbean SIDS have no refugee camps to place forced migrants and refugees that enter their borders. This has resulted in volunteer groups 
assisting with the basic needs of the forced migrant - food, clothing, medical aid and shelter. A forced migrant is a person of concern that has gone through forced migration from their home country; A person of concern is one whose protection and assistance are of interest to the UNHCR (United Nations High Commissioner of Refugees) such as refugees, asylum-seekers, etc. [6]. Trinidad and Tobago faces considerable security challenges and is an active transit point for regional and extra-regional irregular migration to North America and Europe [8]. The current UNHCR guidelines for designing refugee camps seem to be insufficient in solving the different aspects of the problem and accordingly, the camps are becoming overcrowded and fail within a few years [22]. Trinidad has no laws in place for refugees, UNHCR provides those that apply an asylum seeker certification that will permit them to stay within the country, but they are not allowed to work. Thus, many migrants consider their lives on standby until they can voluntarily repatriate or move on to a third country that will permit them to work. Unfortunately, most migrants do not have the means to travel to a third country that accepts refugees and would need to earn the means to do so. Additionally, Trinidad and Tobago has found many documented cases of abuse such as police tearing up asylum papers and detainees being kept in prisons where UNHCR and other partnering NGOs (non-governmental organizations) cannot visit, and deportations of refugees $[8,10]$. Forced migrants are also victims of human trafficking and have poor standard of living within the country. Due to the lack of government intervention and aid the use of volunteers, NGOs, INGOs (international non-governmental organizations), NGOs and NPOs (non-profit organizations) has been crucial in managing the migrant crisis. These organization's efforts are usually not collaborative providing different levels and quality of aid to the forced migrants. Utilizing NGOs to reduce the burden of the government on refugee/forced migrants has been a successful approach in countries such as Japan and Australia. This framework considers the unique problems of SIDS with respect to receiving forced migrants, with Trinidad and Tobago as the case study. It also takes into consideration the drawbacks of traditional refugee camps particularly within developing countries. This study has deduced the following conclusions from investigation of published scholarly literature and current events:

- The traditional, stationary geographically positioned, refugee camp is not a suitable solution for Caribbean SIDS;

- A partnership between NGOs/NPOs and Government is essential to solve the migrant crisis within a developing nation;

- Forced migrants should be integrated with indigenous population in a safe manner;

- Free Open Source Software, FOSS, benefits Caribbean advancement;

- A solution for forced migrants to be sheltered effectively and sustainably is pertinent;

- Forced migrants should be assisted based on international standards such as the Sphere Humanitarian standards and the UNHCR Refugee Protection and Solutions in Urban Areas;

- Lean Startup Methodology and Rapid Application are useful methodologies for requirements gathering, user design and validation.

Based on these conclusions, the research seeks to define a conceptual framework for an eRefugee system based on software technologies. The framework proposes a free open source software, FOSS, concept in which any NGO or government organization can utilize the base framework to meet the demands of the country without having to go through the requirements and analysis phase. Requirements will be methodologically gathered and prioritized to guide analysis and design of 
the core elements of the framework. An open source community can also build and maintain the system. It assumes that all SIDS will be able to capitalize on the output developed by this framework to quickly meet the migration crisis their island is facing. The framework can also be monitored by UNHCR via their UN Online Volunteering system (https://www.onlinevolunteering.org/en). The e-Refugee camp framework will map the movement of migrants within the country and pertinent metadata that will be required for analysis such as age disparity, gender disparity and religion of the migrants, to name a few. This framework targets NGOs and local government ministries such as the Living Waters Community, a partner of UNHCR in Trinidad, to facilitate registration, needs assessment and volunteers needed for the aid and assistance to forced migrants within the country. The GDEC (Geospatially Distributed eRefugee Camp) consists of a network of volunteers of various categories, including but not limited to: hosts or persons that provide shelter by taking the forced migrants into their home (including landlords willing to rent to a forced migrant), medical, legal, transport and education. Volunteers that are hosts to migrants' geographical location can be mapped for ease in tracking and analysis in movement and distribution of aid. Forced migrants will be assigned or connected to a host via Safe Zones. A Safe Zone is an organization, ideally an INGO, NGO, NPO or a government ministry that takes the responsibility to vet volunteers and register forced migrants. Registration will be done via GeoForms for data to be placed within the GDEC system for analysis. A safe zone is also registered via a GeoForm that geographical location and other relevant information for validation. It is pertinent that safe zones and volunteers willing to house refugees conform to the requirements of a refugee settlement identified by UNHCR [9]. The spatial data collected will be secured for administrative access only and exposed in a generic manner via API for future use in analytical or academic purposes. The design for registration and the prioritization of aid to be given to forced migrants, is guided by the literature and standards published by UNHCR and the Sphere Project in addition to feedback from interviews conducted with staff at Living Waters Community and local churches. The Sphere Project is an initiative to determine and promote standards, which the global community utilizes to respond to the plight of people affected by disasters [29]. This project proposes to utilize well defined and tested software development methodologies such as Lean Startup and Rapid Application Development and web and GIS technologies to propose a framework to help foster accurate policy reform. Web services enable Information Technology, IT, to easily embed powerful geographic information systems analysis and mapping capabilities in familiar end-user applications [25]. Proposal of a framework that incorporates web services and technologies such as WordPress, ArcGIS Online, cloud storage; rapid application development and lean startup - a host country should be able to efficiently produce software using the open source community that can capture and monitor forced migrants within their shores and produce web maps for spatial analysis and decision making. Additionally, designed with collaboration in mind, the maps adhere to UNHCR legends and guidelines.

\section{Theoretical Literature Review}

The traditional approach to a refugee camp is a central physical geographic location which temporarily hosts refugees until those housed can be repatriated or integrated into society. It is thought that the benefits of refugee camps are greater efficiency of relief services and enhanced security for both refugees and relief personnel [27]. However, a considerable amount of literature has been published on the extensive limitations of physical refugee camps which have outweighed 
the perceived benefits. These limitations include but are not limited to: mental health such as psychological distress $[12,15,30]$, greater domestic violence towards women, illnesses amongst children under 5 [14], lack of dignity and normalcy [27], and poor health conditions such as chronic illness and spread of infectious diseases [18, 36]. The UNHCR has published policies and standards for designing and implementing refugee camps or settlements, however, UNHCR prefers alternatives to camps, provided they protect and assist people of concern effectively [2]. Literature has been searched widely and the concept of a geospatially distributed refugee camp has not been defined or developed thus far. However, there has been many historical accounts of local community integration as opposed to the traditional refugee camp settlement such as in the case of Angolan refugees settling freely in Zaire or in Zambia, as did Rwandans in Zaire or Tanzania [16]. Forced migrants are also found to organize in rural settlements in remote or forests within the host country. Within Caribbean small island states, the forced migrants are locating in both urban and rural settlements $[10,34]$ and are thus, geographically distributed across the country. A study has found that in the case in which refugees are integrated into the host community, once supported by the local government and the UNHCR, this approach is more cost effective than traditional refugee camps and positively contribute to the economy of the host country [16]. Additionally, the study [16] went on to conclude that sociological and anthropological studies indicate that where refugees could get agricultural land, and were not restricted in movement or access to local employment, they fared better than refugees confined to camps. Literature shows that the use of NGOs to reduce the burden of the government on forced migrants has been a successful approach in island countries such as Japan and Australia [20, 24]. Similar to many Caribbean SIDS, Japan has an obligation to United Nations International Convention relating to the status of refugees and its 1976 and 1981 protocol as a signatory. However, quite similarly to Trinidad and Tobago and Curaçao, Japan has no domestic laws to support the international obligation. Due to this lack of state initiative: the support, assistance and settlement of forced migrants and refugees are carried out mainly by NGOs [17]. Furthermore, the Australian government in 1997 introduced regulations that resulted in unacceptable hardships for forced migrants. In response, a variety of community based agencies/NGOs have been established across Australia [24]. The relationship between a forced migrant crisis and NGOs is prominent in Caribbean SIDS, particularly Trinidad and Tobago and Curaçao where government aid is minimal $[5,11]$. However, NGOs though useful in distributing aid to disfranchised population, are not always equipped or prepared to manage the crisis at hand. The NGOs in Australia were unprepared and under-resourced particularly in relation to housing provision for forced migrants and refugees [24]. A healthy partnership between NGOs and local government requires common standards to efficiently, effectively, uniformly and legally treat the forced migrants. The UNHCR published Refugee Protection and Solutions in Urban Areas guidelines [9] and the Sphere Humanitarian standards [13] which is incorporated in defining the GDEC framework.

Study [21] has shown that refined design principles for refugee camps must support spatial planning and natural resource sustainability while minimizing tension and accounting for the needs, perspectives, and integration of refugees and host communities[1]. Figure 1 below identifies the proposed approach for a refugee camp design managing time, space and resources. In the proposed approach, the refugee settlement should be arranged for long term, integrated within the 
host community and geographically distributed. To efficiently manage a settlement for long term with limited space and resources a technological implementation is most suitable. A specific development goal or objective of the digital agenda in consideration of Caribbean priorities for technology-supported development is to promote open government data initiatives and the use of digital platforms to facilitate collaboration, citizen participation and public transparency [39]. The UNHCR believes that providing open data has become a critical tool in the response to refugee crisis [35]. Having a fully defined and tested framework furthers the ability to provide coordination with direct access to data [35]. The UNHCR has a wide range of GIS technology readily available over the internet. Particularly, the UNHCR has a list of web services implemented, managed and made available using REST (Representational state transfer) technology. The existing web services available include, but are not limited to:

- UNHCR Offices Location;

- UNHCR People of Concern's Location;

- UNHCR Countries and International

These services have recommended legends and support both JSON and GeoJSON queries. PRIMES (Population Registration and Identity Management EcoSystem) is a platform used by UNHCR to provide persons of concern with relevant documentation and management as required, the UNHCR defined PRIMES as an evolving portfolio of applications with the primary objective to furnish refugees and other forcibly displaced populations with a recognized legal and/or digital identity that is recognized by states and businesses safeguarding their protection and empowering them in their daily lives and foster socio-economic inclusion [7]. The PRIMES portfolio includes tools from partners towards to aim of registering and managing refugees and other persons of concern. PRIMES is currently not rolled out in most Caribbean small island states, thus GDEC can fill the gap as a partnering tool allowing all NGOs to have a standard of registering forced migrants and sharing the data to UNHCR in a format they anticipate. The number of households connected to the Internet in the Latin America and Caribbean region grew by 103\% between 2010 and 2016 [28]; this makes internet technologies an appropriate tool for rapid application development to respond to an unplanned crisis. The RAD (Rapid Application Development)

\begin{tabular}{|c|c|c|}
\hline Dimension & Traditional Approach & Proposed New Approach \\
\hline \multirow{2}{*}{ Time } & Temporality & Permanence \\
\cline { 2 - 3 } & Static & Dynamic \\
\hline \multirow{2}{*}{ Space } & Isolation & Integration \\
\cline { 2 - 3 } & One-dimensional & Multi-dimensional \\
\hline \multirow{2}{*}{ Resource } & One-way & Two-way \\
\cline { 2 - 3 } & Physical & Physical, cultural, political, social, economical \\
\hline
\end{tabular}

Figure 2: Refined refugee camp design

software implementation methodology has advantages of ease of implementation, improved user satisfaction and shorter time to market [26]. The scope of the project does not include software implementation, however, the framework is modelled on the premise that RAD will be used for construction and cutover. RAD was utilized in this research for requirements planning and user design which includes prototyping. Lean Startup Methodology is intended to help startup managers avoid significant financial and resource expenses for creating a product that will not be in demand 
on the market [38]. Lean Startup Methodology, specifically aimed to open source canvas, is used to refine the business/product plan and refine user requirements to develop prototyping. Creating a business plan is the first step in applying the Lean Startup Methodology. Fachler [19] coined the term Open Source Canvas as a variation of the Lean Canvas, suited for managing Open Source projects. The Open Source Canvas structures a traditional business plan into a one-page overview with the following categories:

$\begin{array}{ll}\text { - } & \text { Problem } \\ \text { - } & \text { Solution } \\ \text { - } & \text { Unique Value Proposition, UVP } \\ \text { - } & \text { Users } \\ \text { - } & \text { Activities } \\ \text { - } & \text { Channels } \\ \text { - } & \text { Cost and Resources and } \\ \text { - } & \text { Adoption Criteria }\end{array}$

As software implementation is not included in the scope of this project, Lean UX is utilized for feedback and user design validation. The Open Source Canvas was used to identify the value of the Geospatially Distributed e-Refugee Camp framework and how it can be developed and deployed within a small island state with minimal turnover and resources. Ries [31] defined the Minimum Viable Product, MVP, as a version of a new product, which allows a team to collect the maximum amount of validated learning about customers with the least effort possible. An MVP must convince the consumer in its values, as well as confirm or refute the initial hypothesis [38]. The MVP is defined through prioritization of requirements, solution validation and prototype refinement from user feedback. MoSCoW prioritization, also known as the MoSCoW method or MoSCoW analysis, is a popular prioritization technique for managing requirements. MoSCoW groups the requirements into four categories: Must Have, Should Have, Could Have and Won’t Have. The method is commonly used to help key stakeholders understand the significance of initiatives in a specific release [4]. The framework has to be lean and efficient and designed for spatiality. SOMGIS (Service Oriented model for GIS Software Architecture) is a service oriented model which uses SOA (Service Oriented Architecture) concepts as the basic architectural concept and employs OGC (Open Geospatial Consortium) standards to support GIS (Geographic Information System) concerns in the organization [33]. REST is based on representational state transfer (REST) technology, an architectural style and approach to communications often used in web services development [32]. A RESTful API is defined as an application program interface (API) that uses HTTP (HyperText Transfer Protocol) requests to GET, PUT, POST and DELETE data [32]. The RESTful API or web services, is part of the open source model for rapid application development using a service oriented architecture. REST central characteristic is interface uniformity, which decouples implementations from services and gives better interoperability [37]; this makes it the ideal architectural component for the GDEC framework to foster rapid application development using a service oriented architecture. 


\section{Methods}

The research design took three (3) distinct steps to define the GDEC framework:

- Primary and Secondary data collection;

- Application of Software methodologies for requirements gathering and prioritization and interface and conceptual design;

- Evaluation of produced wireframes and requirements.

Following the Lean development process, the following steps were systematically executed with the case study being the Living Waters Community to develop the use case of housing for forced migrants within the GDEC framework:

- Discovery: User Research, Open Source Canvas (see Fig. 2) and Stakeholder Mapping, Current Events, Questionnaires;

- Sketch: Wireframes and User Story Writing;

- $\quad$ Prototype: Rapid prototyping using a CMS (Content Management System), GeoForms and Conceptual Model Design in accordance to SOMGIS;

- Critique: Stakeholder interviews and evaluation of wireframes.

RAD was utilized in this research for requirements planning and user design which includes prototyping. Referencing the Lean Startup Methodology, requirements were prioritized to determine the MVP. Examples of User design include prototyping and low fidelity wireframes. Prototyping was used to quickly incorporate feedback from users into a solution design [23]. The

\begin{tabular}{|c|c|c|c|c|}
\hline \multirow[t]{2}{*}{$\begin{array}{l}\text { - Inability for Trinidada and Tobago } \\
\text { and other small islands, to } \\
\text { ressond to an unexpected mass } \\
\text { migrant flow within the country; } \\
\text { Inability to efficiently connect } \\
\text { volunteers or wiling persons to } \\
\text { those in need, such as the forced } \\
\text { migrants or refugees. }\end{array}$} & $\begin{array}{l}\text { Solution } \\
\text { - Virtual Refugee Camp: a } \\
\text { sottware solution to capture, } \\
\text { connect, manage and track the } \\
\text { arrival, settlement and movement } \\
\text { of forced migrants. }\end{array}$ & \multirow[t]{2}{*}{$\begin{array}{l}\text { Unique Value } \\
\text { Proposition } \\
\text { - Use of technology to } \\
\text { respond in a cost effective } \\
\text { manner to a humanitarian } \\
\text { crisis with an emphasis of } \\
\text { burden sharing between } \\
\text { government and private } \\
\text { organizations. }\end{array}$} & $\begin{array}{l}\text { Community Relationships } \\
\text { - Government; } \\
\text { NGOlunteer Network: Charities, } \\
\text { NGOS, NPOS, volunteers; } \\
\text { - UNCR; } \\
\text { bastware engineers for RAD } \\
\text { basen VRC solution model. }\end{array}$ & $\begin{array}{l}\text { - Forced Migrants; } \\
\text { - Non-governmental } \\
\text { agencies/Charities; } \\
\text { - Government } \\
\text { agencies/ministries }\end{array}$ \\
\hline & $\begin{array}{l}\text { Activities } \\
\text { - Rapid prototyping } \\
\text { - API Generation } \\
\text { Technology modelling for RAD }\end{array}$ & & $\begin{array}{l}\text { Channels } \\
\text { - Conferences held at } \\
\text { NGOs/NPOs/Charities/Religious } \\
\text { institutions } \\
\text { - Web, Social media etc. } \\
\text { - Face to face (meetups, conferences } \\
\text { etc.) } \\
\text { - Mobile applications } \\
\text { - Websites }\end{array}$ & \\
\hline \multicolumn{2}{|c|}{ 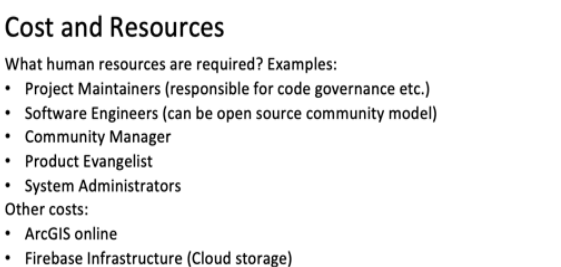 } & & \multicolumn{2}{|c|}{$\begin{array}{l}\text { Adoption Criteria } \\
\text { - Size of volunteer network } \\
\text { - Number of successful connections (match between host volunteer and forced } \\
\text { migrant) } \\
\text { Number of contributors to code base for one implementation and rollout }\end{array}$} \\
\hline
\end{tabular}

Figure 3: Open Source Canvas for GDEC 
RAD methodology allows speedy prototyping and working code for user validation. RAD in conjunction with Lean Startup Methodology would allow an accurate abstraction of the GDEC software implementation by producing the Minimal Viable Product, MVP, recommended software architecture, conceptual model and API Design.

\section{Discussion and Results}

This study aimed to define a conceptual framework for a geospatially distributed e-Refugee camp within the Caribbean SIDS by use of a case study model. Trinidad and Tobago was used for the case study for ease of collecting primary data. This framework is purposed to manage shelter and track forced migrants using technology in a cost effective manner. Geospatial analysis will be used to determine best matches between volunteers and forced migrants based on volunteer preferences, overall suitability and forced migrant needs assessment. ArcGIS GeoAnalytics such as FindSimilarLocations and ChooseBestLocation, can be used in implementation to produce these matches. ArcGIS GeoForms are used to register both volunteers and forced migrants. Volunteers that are willing to host forced migrants have to be screened to ensure that their accommodation adheres to UNHCR guidelines for a refugee settlement. Once screened, a host volunteer is a shelter within the GDEC refugee settlement. The resulting depiction of forced migrants, hosts (volunteers and landlords) and other relevant public services within Trinidad and Tobago creates the Geospatially Distributed e-Refugee Camp (see Fig. 3 below). The symbology was selected based

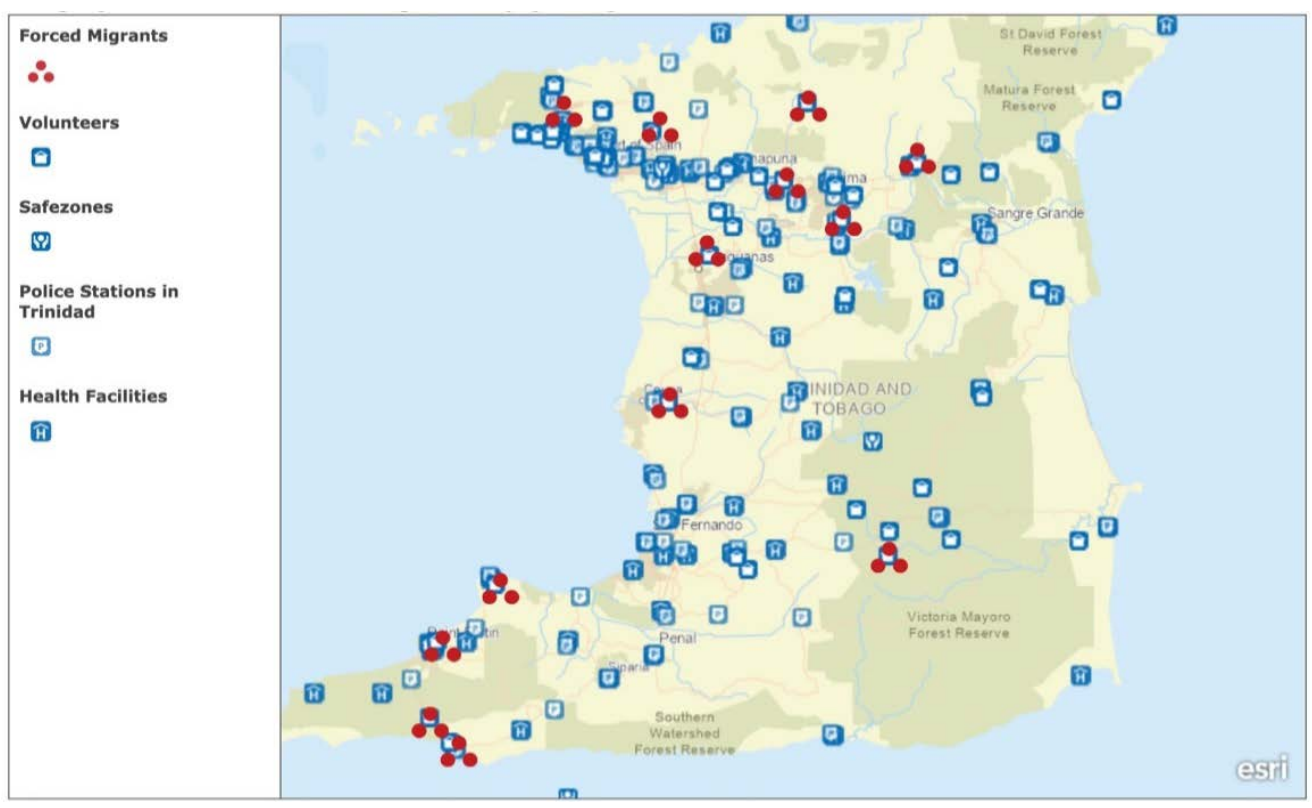

Figure 4: Geospatially distributed eRefugee system in ArcGIS

on UNHCR legend guidelines. Having a GIS, specifically GDEC, can aid local government to better prepare and analyze the effect immigration has on local services such as policing, health, schools and the services being consumed by the forced migrant community such as English as a Second Language. This analysis can aid government(s) in decision making, planning and creating/modifying domestic laws regarding forced migrants. Furthermore, data can be sent to 
UNHCR that their aid and reporting can be guided accordingly and efficiently. A great advantage of GDEC is the screening process and training for volunteers to adhere to Sphere Humanitarian standards [13]. It is hoped that this will greatly reduce the number of human rights violation that occur and protect the forced migrant population.

User design was validated using low fidelity wireframes and rapid prototyping using a CMS and embedded GeoForms. Based on the lean startup methodology and MVP principle, a landing page was created using WordPress, this allowed key stakeholders to register and test the Geospatially Distributed e-Refugee Camp framework via GeoForms. Additionally, wireframes/UI (User Interface) mock-ups were used and tested for feedback and validation with personnel at Living Waters Community and volunteers at a community church. See below for a sample of wireframes and screenshots created based on the highest prioritized user stories. Three GeoForms were created to populate the feature layers within the ArcGIS system:

- Forced Migrants registration;

- Safe Zone registration;

- Volunteer registration.

Construction and cutover can be implemented using an open source volunteer platform to encourage citizen participation and rapid development at low cost. Management of the data, infrastructure and volunteer team is the responsibility of the implementing country.

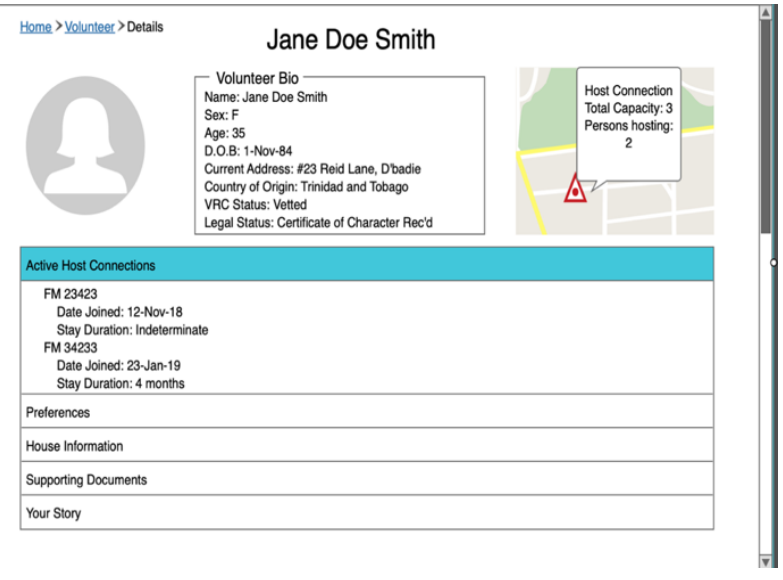

Figure 5a: Wireframe for Volunteer information

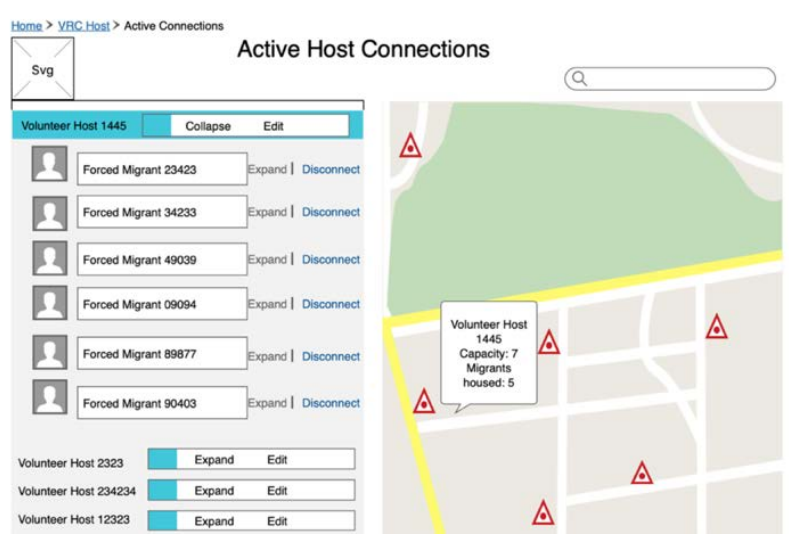

Figure 6b: Wireframe for active housing connections

\section{Conclusion and Future Work}

The movement and displacement of forced migrants is a spatial problem at its core. The Caribbean's small island developing states is ill-equipped to deal with a large uninvited migratory movement within its shores particularly to vulnerable individuals in need of shelter and protection. These small island states do not have the man-power or geographical space to adhere to traditional refugee settlements, however out of necessity, the forced migrants have integrated with the indigenous populace and are working to provide themselves food and shelter. The use of 
technology to advance the Caribbean's ability, knowledge and preparedness to manage a migratory crisis is the most cost effective and efficient solution to the problem at hand.

The success of the GDEC is highly dependent on burden sharing between government and NGOs. A Government partnership is critical for legal support and successful dissemination of information to the wider public. Additionally, there is enormous opportunity for a burden-sharing model across small island states. Guyana is establishing temporary settlement for Venezuelan refugees [3] and citizens residing near the border have willingly opened their homes to Venezuelan citizens. Within a regional burden sharing model, Guyana can receive forced migrants from small island states and financial support to accommodate and integrate them into their country, or settle them into the refugee settlement. For example, if Curaçao's volunteer network is insufficient to host the forced migrant populace within its shores, via the GDEC implementation, forced migrants can be connected to hosts in other Caribbean countries such as Trinidad and Tobago or Guyana that has a larger capacity or host volunteers, thus hopefully a larger volunteer network, thereby creating a Caribbean Geospatially Distributed e-Refugee Camp. With similar models such as Caribbean Community (CARICOM), Caribbean Court of Justice (CCJ) and the Single Market and Economy (CSME); a Trinidad and Tobago GDEC seems like the most logical next step in solidifying the GDEC Framework. With the framework developed using Lean Startup Methodology and Rapid Application Development, a skillful group of technologists should be able to roll-out an implementation efficiently to meet the problems being faced.

\section{References}

[1] Camp planning standards (planned settlements). UNHCR The UN Refugee Agency|Emergency Handbook.

[2] Camp planning standards (planned settlements). [cited 2019; Available from: https://emergency.unhcr.org/entry/248797/camp-planning-standards-planned-settlements.

[3] Guyana to establish temporary settlement for Venezuelan refugees, in Jamaica Observer. 2018.

[4] MoSCoW Prioritization. Available from: https://www.productplan.com/glossary/moscowprioritization/.

[5] The Netherlands Should Protect Venezuelan Refugees. Targeted News Service, 2018.

[6] Policy on the Protection of Personal Data of Persons of Concern to UNHCR. 2015, UN High Commissioner for Refugees (UNHCR).

[7] Registration and Identity management. PRIMES; Available from: https://www.unhcr.org/registration.html.

[8] TRINIDAD AND TOBAGO. [cited 2018; Available from: https://www.iom.int/countries/trinidad-and-tobago.

[9] UNHCR policy on refugee protection and solutions in urban areas 2009, UNHCR The UN Refugee Agency.

[10] US\$1.5 million community project launched to help with Venezuelans. 201926 September 2019; Available from: http://www.looptt.com/content/community-project-launched-helplocals-treat-venezuelan-influx.

[11] The Venezuelan Exodus. 2018; Available from:

https://www.hrw.org/report/2018/09/03/venezuelan-exodus/need-regional-responseunprecedented-migration-crisis. 
[12] Anna Ziersch, M.W., Clemence Due, and Emily Duivesteyn, Exploring the Relationship between Housing and Health for Refugees and Asylum Seekers in South Australia: A Qualitative Study. International Journal of Environmental Research and Public Health, 2017. 14(9).

[13] Association, S., The Sphere Handbook, in Humanitarian Charter and Minimum Standards in Humanitarian Response. 2018, Practical Action Publishing: Geneva, Switzerland.

[14] Christine L Hershey, S.D., Jamie Anderson, Christopher Haskew, Paul Spiegel and William J Moss, Incidence and risk factors for Malaria, pneumonia and diarrhea in children under 5 in UNHCR refugee camps: A retrospective study. Conflict and Health, 2011. 5(1): p. 24.

[15] Clark, N., Exploring community capacity: Karen refugee women's mental health. International Journal of Human Rights in Healthcare, 2018. 11(4): p. 244-256.

[16] Damme, W.V., Do refugees belong in camps? Experiences from Goma and Guinea. The Lancet, 1995. 346(8971): p. 360-362.

[17] Dean, M., and Miki Nagashima., Sharing the Burden: The Role of Government and NGOs in Protecting and Providing for Asylum Seekers and Refugees in Japan. Journal of Refugee Studies, 2007. 20(3): p. 481-508.

[18] Dr. Rima R Habib, K.S., Safa Hojeij, Health and living conditions of Palestinian refugees residing in camps and gatherings in Lebanon: a cross-sectional survey. Lancet, 2012. 380(1).

[19] Fachler, G. A business plan for your open source project. 2016; Available from: https:/opensource.com/article/16/12/open-source-canvas.

[20] Fleay, C., L. Hartley, and M.A. Kenny, Refugees and asylum seekers living in the Australian community: the importance of work rights and employment support. Australian Journal of Social Issues (John Wiley \& Sons, Inc. ), 2013. 48(4): p. 473-493.

[21] Jahre, M.K., Joakim; Adjahossou, Anicet; Altay, Nezih, Approaches on design of refugee camps - An empirical study in Kenya, Ethiopia, Greece and Turkey. Journal of Humanitarian Logistics and Supply Chain Management, 2018. 8(3).

[22] Kennedy, J., Challenging camp design guidelines. University of Oxford, 2005(23): p. 4647.

[23] Liou, F.W., Rapid Prototyping And Engineering Applications. 2007.

[24] McNevin, A. and I. Correa-Velez, Asylum seekers living in the community on Bridging Visa E: Community sector's response to detrimental policies. Australian Journal of Social Issues (Australian Council of Social Service), 2006. 41(1): p. 125-139.

[25] Mitchell, R.L., Web Services put GIS on the Map. Computerworld, 2003. 37(50): p. 30-31.

[26] Nik Marsyahariani Nik Daud, N.A.A.A.B.a.H.M.R., Implementing rapid application development $(R A D)$ methodology in developing practical training application system. 2010 International Symposium on Information Technology, 2010.

[27] Oka, R.C., Coping with the Refugee Wait: The Role of Consumption, Normalcy, and Dignity in Refugee Lives at Kakuma Refugee Camp, Kenya. American Anthropologist, 2014. 116(1): p. 23 -37.

[28] Poveda, E.F.R.a.L., State of broadband in Latin America and the Caribbean. 2017, Unitad Nations ECLAC: Santiago.

[29] Reed, B. Developing Water And Capacity In Water Engineering And Development Worldwide. The Sphere Project 2014; Available from: 
https://reliefweb.int/sites/reliefweb.int/files/resources/G012-The-Sphere-Projectonline.pdf.

[30] Richard F. Mollica, K.D., Svang Tor, James Lavelle, Christopher Elias, Martin Frankel, Robert J. Blendon, THE EFFECT OF TRAUMA AND CONFINEMENT ON FUNCTIONAL HEALTH AND MENTAL-HEALTH STATUS OF CAMBODIANS LIVING IN THAILAND-CAMBODIA BORDER CAMPS. JAMA: Journal of the American Medical Association, 1993. 270(5): p. 581 -586.

[31] Ries, E. Creating the Lean Startup. 2011.

[32] Rouse, M. RESTful API (REST API). A DevOps tutorial on migrating to microservices; Available from: https://searchapparchitecture.techtarget.com/definition/RESTful-API.

[33] Sadjedy, A.A.a.S. SOMGIS-A Service Oriented Model For GIS Software Architecture. in 2nd International Conference on Computer Engineering and Technology.

[34] Silva, R.D., Venezuelans hide in forest; feed on mangoes, coconuts, in Trinidad and Tobago Guardian. 2019, Guardian: guardian.co.tt.

[35] Smith, N. 2013; Available from: https://medium.com/devseed/unhcr-relaunches-dataunhcr-org-d700033b35e4.

[36] Sullivan, P., Poor conditions in refugee camps make malaria screeing difficult: Expert. CMAJ: Canadian Medical Association Journal, 2000. 163(8): p. 1036.

[37] Takeru INOUE, H.A., Yukio UEMATSU, Hiroshi SATO, Noriyuki TAKAHASHI, Web API Database Systems for Rapid Web Application Development. IEICE Transactions on Information and Systems. E93.D(12): p. 3181-3193.

[38] Veretennikova, N., and Roman Vaskiv, Application Of The Lean Startup Methodology In Project Management At Launching New Innovative Products, in IEEE 13Th International Scientific And Technical Conference On Computer Sciences And Information Technologies (CSIT). 2018.

[39] Williams, R.C., Working paper on the eLAC 2018 Digital Agenda in consideration of Caribbean priorities for technology-supported development, in Economic Commission for Latin America and the Caribbean (ECLAC). 2015, United Nations. 